\title{
Salicylic Acid and Water Stress Effects on Growth and Proline of Cucumber Seedlings
}

\author{
Gui-Soon Lee, Tae-Yun Kim, and Jung-Hee Hong \\ Dept. of Biology, Pusan National University, Busan 609-735, Korea \\ (Manuscript received 23 October, 2002 ; accepted 5 December, 2002)
}

\begin{abstract}
The effects of salicylic acid(SA) and water deficit on growth and proline accumulation were investigated in cucumber(Cucurmis sativus L.) seedlings. Exogenous application of SA(100 $\mu \mathrm{M}-1 \mathrm{mM}$ ) led to a noticeable decrease in root and shoot growth, and dry weight of seedlings. Anatomical observation on leaf of cucumber revealed that the thickness of all leaf tissue components decreased in SA-treated plants. The effect was most pronounced on the width of the adaxial epidermis. In the separate effects of $\mathrm{SA}(0,100,500$ and $1000 \mu \mathrm{M})$ and water deficit induced by PEG $(0,4.4,7.0$ and $9.6 \%)$ on growth, the water deficit treatments had greater effects on growth traits than SA. Combinations of SA and PEG(SA+PEG) decreased shoot and root dry matter, and root length. Proline increased slightly in SA-treated seedlings, but exhibited a marked increase in water deficit application. Combinations of SA+PEG induced higher proline in both shoots and roots than SA stress alone. Shoots had higher proline than roots. Our data support a role of SA potentiating the osmotic stress response of germinating cucumber seedling.
\end{abstract}

Key words : salicylic acid, water deficit, proline, adaxial epidermis, dry matter, root length, Cucurmis sativus

\section{Introduction}

Salicylic acid(SA), an natural plant phenolic, was recognized as an endogenous regulator in plants after the finding that is involved in many plant physiological processes. SA was detected in the leaves and reproductive organs of agronomically important species"). One of the most studied functions of SA is associated with its involvement in plant resistance response to different pathogen attacks ${ }^{2)}$. Exogenous application of SA to plants exerts diverse physiological and biochemical effects ${ }^{3)}$, such as inhibition of dry mass accumulation $^{4)}$ and sugar and amino acid uptake ${ }^{5 \text {, }}$, promotion of stomatal closure ${ }^{6)}$, control of ion uptake and transport through the root membranes ${ }^{7)}$ and inhibition of ethylene synthesis ${ }^{8)}$. In a num-

Corresponding author ; Jung-Hee Hong, Dept. of Biology, Pusan National Univ., Busan, 609-735, Korea Phone : +82-51-510-2263

E-mail : jhhong@pusan.ac.kr ber of species, SA promoted flowering in combination with other plant growth regulators ${ }^{9}$, and marked increases in anthocyanins and chlorophyll content in SA-treated Spirodela were observed ${ }^{10)}$. Evidence for the involvement of SA in induction of an alternative respiratory pathway ${ }^{11)}$ and expression of nuclear gene encoding the alternative oxidase protein in Sauromatum guttatum ${ }^{12)}$ has been presented. As a result of SA treatment, breakdown in the synthesis of ribulose -1,5biphosphate carboxylase/oxygenase(RuBPCO ${ }^{13)}$ and an inhibition of the Hill reaction activity ${ }^{14)}$ as well as changes in net photosynthetic rate, carotenoid and sugar contents ${ }^{15)}$ were reported. Although the focus has been mainly on the role of SA biotic stresses, it was reported that SA also accumulates during exposure to ozone or UV light ${ }^{16,17}$. SA has also been implicated in protection against chilling ${ }^{18)}$ and heat shock ${ }^{19}$. SA is now considered as an hormone-like substance and is recognized as a key signal molecule involved in local and systemic responses to viral infection ${ }^{20,21)}$. 
Pancheva et al. ${ }^{22)}$ showed that treatment of barley with SA exericised a considerable effect on the growth of the seedlings. Leaf emergence was delayed, blades expanded more slowly over a longer period of time, and mature blades were both narrow and shorter. The anatomical observations were focused on leaf anatomy, particularly on chloroplasts, because thylakoids undergo the greatest changes during adverse environmental conditions, such as drought, heavy metals, or after exogenous treatment with growth regulators ${ }^{23}$. The observed inhibition in the rate of photosynthesis may be related to the changes of the membrane structure of chloroplasts.

Environmental stresses such as salt and drought are among the factors most limiting to plant productivity. Such stresses are becoming even more prevalent as the intensity of agriculture increases. Therefore, elucidation of the mechanisms by which plants perceive and transduce these stresses in critical if we are to understand the plant response and introduce genetic or environmental improvement to stress tolerance. Drought and salt tolerance are developmentally regulated, stage-specific phenomena because tolerance at one stage of plant development is not necessarily correlated with tolerance at other stages ${ }^{24)}$. The mechanisms of tolerance at specific stages of plant development, such as seed germination, were investigated by many authors with special regard to the biochemical events that play an important role in the responses to abiotic stresses.

There are well established metabolic traits leading to proline accumulation under stress conditions that are assumed to be involved in stress tolerance ${ }^{25}$. However, there is no definite evidence for the adaptive value of proline itself under adverse conditions. Kishor et al. ${ }^{26)}$ observed increased resistance to water deficit and salinity stress in transgenic tobacco plants, but could not conclude whether stress resistance was enhanced by proline over-accumulation or by some other mechanism. The adaptive significance of proline accumulation in higher plants during stress remains uncertain, but it appears that cells use them as osmolytes to regulate cell water pressure ${ }^{27)}$.

The aim of this study was to determine the effects of SA and water deficit, administered separately and in combination, on growth traits and pro- line accumulation in cucumber seedlings. Detailed comparisons of separate and combined effects between SA and water deficit would help identify plants for tolerance to these factors to enhance plant improvement procedures.

\section{Materials and Methods}

\subsection{Plant material}

Seeds of cucumber(Cucurmis sativus L.) were germinated for $2 \mathrm{~d}$ in 2 layers of moist filter paper in moist vermiculite in the dark at $25{ }^{\circ} \mathrm{C}$, allowing for some air exchange. At either 2 or $3 \mathrm{~d}$ after sowing, the seedlings were grown in a growth chamber at $25 / 20{ }^{\circ} \mathrm{C}$ day/night, $12 \mathrm{~h}$ photoperiod, light intensity of $200 \mu \mathrm{mol} \mathrm{m}^{-2} \mathrm{sec}^{-1}$ under white fluorescent lamps and relative humidity of $60 \pm 5 \%$.

\subsection{Growth conditions and measurement}

The seedlings were placed in two layers of moist filter paper in Petri dishes containing $40 \mathrm{~mL}$ distilled water or equal amount of water solution of the required SA concentrations $(100,500$ and $1000 \mu \mathrm{M})$. Stock of SA(Sigma) was prepared in a small volume of ethanol(final concentration $1 \%$ ), diluted to its final concentration in water, and kept refrigerated until use. The solution was changed every $24 \mathrm{~h}$.

Short-term experiments( 4 or 7 days) were designed to study early growth kinetics. To monitor growth, lengths and widths of seedlings were measured to the nearest $0.5 \mathrm{~mm}$ using a magnifying lens and graph paper printed with $1.0 \mathrm{~mm}$ markings. Initial and final fresh and dry weights of the seedlings were determined. Dry weights were measured after incubation the samples at $60{ }^{\circ} \mathrm{C}$ for $12 \mathrm{~h}$. For anatomical observations, leaf samples were taken at mid-lamina from the second leaf of 10-d-old seedlings and fixed with $2.5 \%$ glutaraldehyde in phosphate buffer( $\mathrm{pH}$ 7.4). The thickness of the lamina between bundles was examined. Cross sections were cut by hand.

To determine the effects of SA and water deficit on seedling growth, 7-d-old seedlings were transferred to plastic tray submerged in half-strength Hoagland solution ${ }^{27)}$ and grown for an additional $3 \mathrm{~d}$. Uniform sized seedlings were transferred to $1.9 \mathrm{~L}$ containers(4 plants/container) and grown an additional $4 \mathrm{~d}$ with full-strength Hoagland solution. At this time, plants received new full-strength 
solutions containing SA and water deficit treatments, and grown an additional $10 \mathrm{~d}$ before experiments were terminated. Experiment 1 treatments consisted of $0,100,500$ and $1000 \mu \mathrm{mol} / \mathrm{L}$ SA and water deficit was induced with polyethylene glycol-8000(PEG) at 4.4, 7.0 and $9.6 \%(w / w)$ in solution(equivalent to approximately $-0.09,-0.13$ and $-0.17 \mathrm{MPa}$ ) as separate treatments. Combination of 0,200 and $500 \mu \mathrm{M}$ and $0,4.4$ or $7.0 \%$ PEG made up the treatments for Experiment 2.

\subsection{Acidity content}

Total titratable acidity was measured in the leaf tissue of 7-d-old seedlings ${ }^{13)}$. $0.5 \mathrm{~g}$ fresh material collected from different plants was ground in a prechilled mortar and pestle with $50 \mathrm{~mL}$ of $\mathrm{CO}_{2}$-free distilled water and filtered through four layers of cheese-cloth. An aliquot(2-4 mL) of the homogenate was titrated with $0.01 \mathrm{M} \mathrm{KOH}$ (prepared freshly in $\mathrm{CO}_{2}$-free distilled water) to an end point of $\mathrm{pH} 7.0$. Acidity was expressed as $\mu$ equivalents/g fresh weight.

\subsection{Proline determination}

The protein contents were determined according to Bates et $\mathrm{al}^{28)} .0 .5 \mathrm{~g}$ of the plant material was homogenized in $10 \mathrm{~mL}$ of $3 \%$ aqueous sulfosalicylic acid and the homogenate was centrifuged at $1,500 \mathrm{~g}$ for $10 \mathrm{~min}$. A $2 \mathrm{~mL}$ aliquot of the supernatant was mixed for reaction with $2 \mathrm{~mL}$ acidic ninhydrin and $2 \mathrm{~mL}$ of glacial acetic acid in a test tube for $1 \mathrm{~h}$ at $100{ }^{\circ} \mathrm{C}$. The mixture was extracted with $4 \mathrm{~mL}$ toluene. The extract was vigorously mixed for $20 \mathrm{sec}$. The chromophorecontaining toluene was then separated and its absorbance was spectrophotometrically determined at $520 \mathrm{~nm}$ using toluene for a blank. The proline concentrations were calculated on a fresh weight basis.

Data were statistically evaluated by the standard deviation and $\mathrm{T}$-test methods. The results presented are combined from at least 3 replicated experiments for survival data, or at least 2 replicated experiments for biochemical measurements.

\section{Results and Discussion}

\subsection{Effects of SA on the seedling growth and leaf anatomy}

Treatment of cucumber with SA exercised a considerable effect on the growth of the seedlings (Table 1). Concentrations of the order of $100 \mu \mathrm{M}$ to $1000 \mu \mathrm{M}$ tended to inhibit growth. The concentrations lower than $100 \mu \mathrm{M}$ SA had no effect on the seedling growth, while concentrations of SA higher than $1000 \mu \mathrm{M}$ completely inhibited the seedling growth(data not shown). In the experiments carried out with three levels of SA treatment, proline levels increased with increasing SA concentrations. The most prominent effect was at $1000 \mu \mathrm{M} \mathrm{SA}$, an over threefold rise as compared with the control. Relative to control, SA-treated seedlings also exhibited a higher accumulation of leaf titratable acidity. The extent of changes in titratable acidity was not strong as that of changes in proline levels. The increase in the values of this parameters occurred much lower than those observed for proline content. $100 \mu \mathrm{M} \mathrm{SA}$ had no effect on the level of titratable acidity. The increased values of proline content and titatable acidity claim that $S A$ could provide alterations very often associated with plant responses to stressrelated reactions. Further study of the changes in the endogenous levels of SA after exposure of plants to environmental stresses seems warranted.

Application of SA reduced cell elongation in root length, and the degree of inhibition of root length was dependent upon the SA supply, indicating that root growth rate was correlated with external SA concentrations(Fig. 1). These effects of SA on cucumber root are quite similar to those on barley roots ${ }^{22}$. Time course of the root elongation is shown in Fig. 2. Significant effect of $\mathrm{SA}$ on growth was observed on the second day of incubation, suggesting that SA affect the seed germination. The effects of SA on elongation and

Table 1. Effects of SA on the growth, proline accumulation and the values of titratable acidity in cucumber seedlings

\begin{tabular}{cccc}
\hline $\begin{array}{c}\text { SA } \\
(\mu \mathrm{M})\end{array}$ & $\begin{array}{c}\text { Length of } \\
\text { seedlings } \\
(\mathrm{cm})\end{array}$ & $\begin{array}{c}\text { Proline } \\
\text { content } \\
\left(\mu \mathrm{molg}^{-1} \mathrm{FW}\right)\end{array}$ & $\begin{array}{c}\text { Titratable } \\
\text { acidity } \\
\left(\mu \mathrm{eqg}^{-1} \mathrm{FW}\right)\end{array}$ \\
\hline $0($ control $)$ & $12.60 \pm 0.14$ & $1.4 \pm 0.5$ & $11.1 \pm 0.4$ \\
100 & $11.39 \pm 0.23$ & $2.5 \pm 0.4$ & $11.5 \pm 0.2$ \\
500 & $8.43 \pm 0.15$ & $4.4 \pm 0.5$ & $14.8 \pm 0.4$ \\
1000 & $7.85 \pm 0.25$ & $5.5 \pm 0.4$ & $15.9 \pm 0.4$ \\
\hline
\end{tabular}




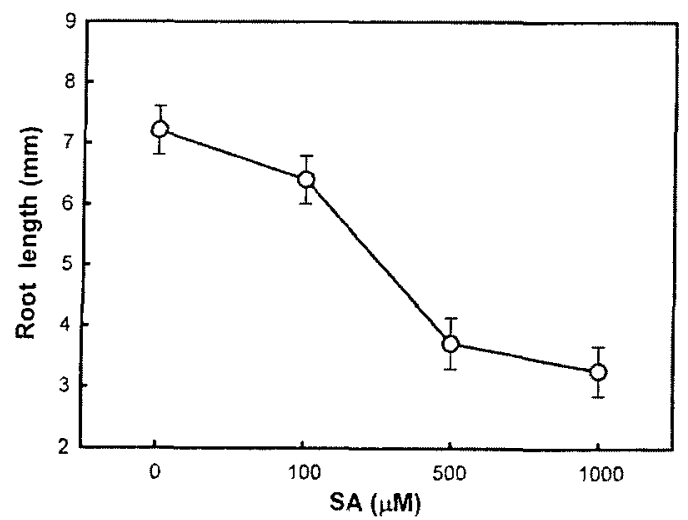

Fig. 1. Effects of SA on the root elongation in cucumber seedlings grown for 4 days in the dark.

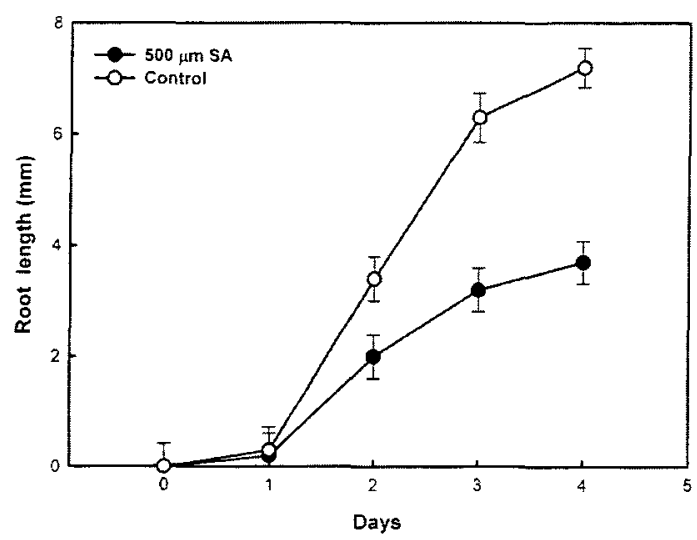

Fig. 2. Time course of root elongation of cucumber seedlings exposed to $500 \mu \mathrm{M}$ SA for 4 days.

lateral expansion appeared in the subsequent incubation period.

In control leaves, the thickness of the lamina decreased with an increase in SA concentration (Table 2). The abaxial epidermis consisted of cells almost equal in size. The mesophyll tissue was composed of loosely packed mesophyll cells, and the vascular system was well developed between the bundles. Distinct diffences were observed in leaf components of the control and SA-treated cucumber seedlings. The average thickness of the lamina declined with increasing concentrations. A marked reduction in the width of the adaxial and abaxial epidermis was observed in ali SA-treated plants. The reduction of epidermal width was more pronounced on the adaxial epidermis. The distance between bundles was also reduced. The morphometric values showed that treatment of $\mathrm{cu}$ cumber with 100 and $500 \mu \mathrm{M}$ SA caused a uniform decrease in the thickness of adaxial and abaxial epidermis. The mesophyll tissue was also thinner compared to the controls, the effect being more expressed at higher application of SA concentrations. Morphometric values indicated that the epidermal tissue of plants treated with $1 \mathrm{mM} \mathrm{SA}$ consisted of smaller cells. The cells of adaxial epidermis were smaller in size in SA-treated plants as compared with the control. Recently, Uzunova and Popova ${ }^{29)}$ reported a similar result in the barley. It has been proposed that treatment of barley seedlings with SA reduced leaf and root growth, and rate of photosynthesis ${ }^{22)}$. Other authors have shown that SA and other phenolic compounds may reverse ABA-induced stomatal closure in Lemma gibba ${ }^{30)}$. The successful operation of photosynthetic reation is dependent upon the presence of reaction components, their specific organization within photosynthetic cells, and their being under control of environmental factors and hormonal status of the plant ${ }^{29}$. It was hypothesized that the observed photosynthetic differences among untreated and SA-treated plants could be partially due to differences in internal organization of leaf tissues and by their ability to produce ATP and reducing

Table 2. Morphometric values of thickness of leaf lamina and its tissue components $(\mu \mathrm{m})$ of cucumber plants after treatment with SA

\begin{tabular}{cccccc}
\hline $\begin{array}{c}\text { SA } \\
(\mu \mathrm{M})\end{array}$ & $\begin{array}{c}\text { Thickness of lamina } \\
\text { between bundles }\end{array}$ & $\begin{array}{c}\text { Adaxial } \\
\text { epidermis }\end{array}$ & $\begin{array}{c}\text { Abaxial } \\
\text { epidermis }\end{array}$ & Mesophyll & $\begin{array}{c}\text { Distance } \\
\text { between bundles }\end{array}$ \\
\hline 0 & $38.34 \pm 3.28$ & $11.42 \pm 1.27$ & $8.52 \pm 1.13$ & $16.40 \pm 3.04$ & $99.52 \pm 8.37$ \\
100 & $32.82 \pm 0.78$ & $7.60 \pm 1.25$ & $7.60 \pm 1.20$ & $16.12 \pm 4.49$ & $83.64 \pm 7.03$ \\
500 & $27.60 \pm 3.03$ & $5.62 \pm 1.60$ & $5.60 \pm 1.05$ & $14.72 \pm 3.13$ & $73.62 \pm 8.46$ \\
1000 & $25.82 \pm 3.32$ & $3.33 \pm 0.98$ & $6.10 \pm 1.76$ & $13.68 \pm 1.20$ & $61.65 \pm 8.03$ \\
\hline
\end{tabular}


equivalents. Many of the observed plant responses to SA may have adaptive significance because they conserve water. Probably the most significant among the morphological changes is the reduction of leaf expansion. This is a common effect of stress that tends to reduce the total transpiring area. Analogous results were observed as an effect of salinity stress ${ }^{31)}$ or after treatment of barley plants with jasmonic acid ${ }^{32)}$. In summary, the results show that SA treatment to cucumber seedlings causes alterations in leaf anatomy, suggesting that exogenous SA application decreases photosynthetic activity as a result of effects on the thylakoid membranes and light-induced reactions connected them. The lower leaf photosynthetic area and probably changes in its water balance could be another possible explanation.

\subsection{Effects of SA and water stress on growth and proline content}

The effects of $\mathrm{SA}(0,100,500$ and $1000 \mu \mathrm{M})$ and water deficit induced by PEG $(0,4.4,7.0$ and $9.6 \%$ ), administered separately and in combination, on growth traits and proline accumulation in shoots and roots of cucumber were determined. Plants grown with the highest levels of SA had root length less than half that of 0 and $100 \mu \mathrm{M} \mathrm{SA(Fig.} \mathrm{3).}$ Roots of plants grown in PEG had little change
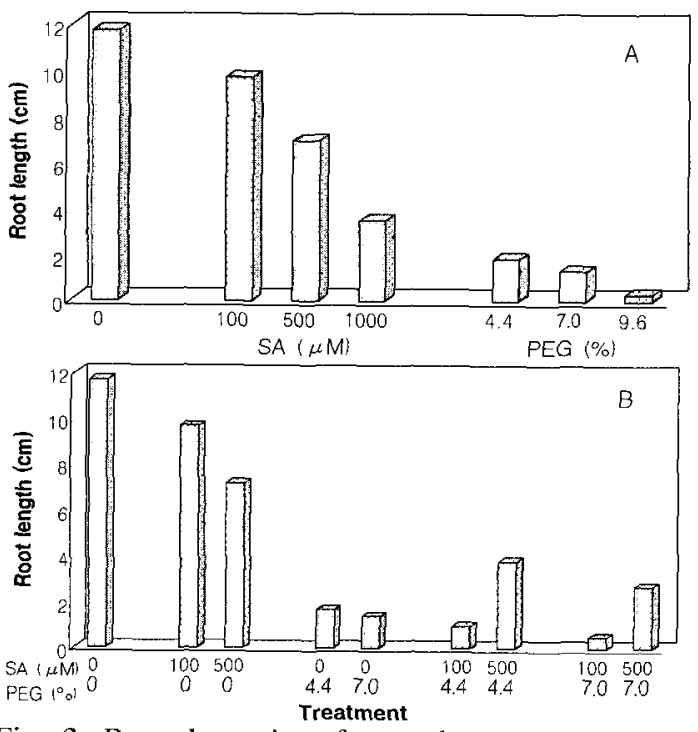

Fig. 3. Root elongation of cucumber seedlings grown with SA and PEG alone( $A$ ) and in combination(B). in root length ; that is, the roots did not elongate when PEG was added. Increased levels of SA and PEG progressively decreased root length ; PEG treatments had a greater effect than SA. Plants grown with $1 \mathrm{mM} \mathrm{SA}+9.6 \%$ PEG combined died within 4 to 5 day after addition, so the results of this treatment are not shown. Growth traits for plants grown with the 100 and $500 \mu \mathrm{M} \mathrm{SA}$ and $4.4 \%$ and $7.0 \%$ PEG treatments separately were relatively similar to those presented in dry matter. The root length for plants growth with $500 \mu \mathrm{M}$ $\mathrm{SA}+7.0 \%$ PEG was $87 \%$ lower compared to control plants. The root length of plants grown with various $\mathrm{SA}+\mathrm{PEG}$ treatments were lower than for control plants. The SA+PEG treatments had relatively little effect on root length.

Cucumber had higher shoot dry matter than control when plants were grown with $100 \mu \mathrm{M} \mathrm{SA}$ (Fig. 4). However, shoot dry matter decreased at concentration higher than $500 \mu \mathrm{M}$ SA. Shoot and root dry matter decreased as water deficit increased. Plants grown with high water deficit had greater decrease in shoot and root dry matter than plants grown with high SA. Shoot and root dry matter was lower in most cases when SA and PEG were combined compared to separate SA and
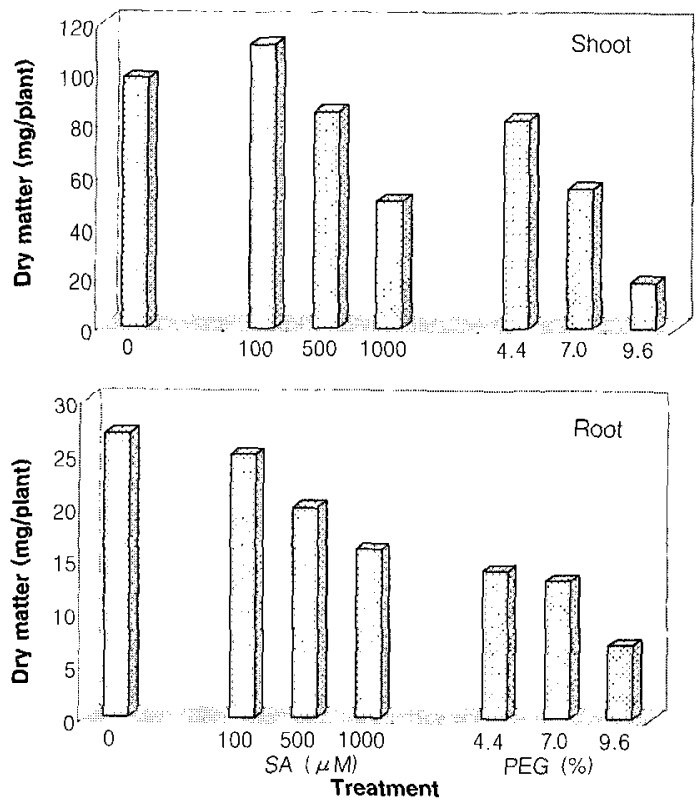

Fig. 4. Shoot and root dry matter of cucumber seedlings exposed to different concentrations of SA and PEG. 


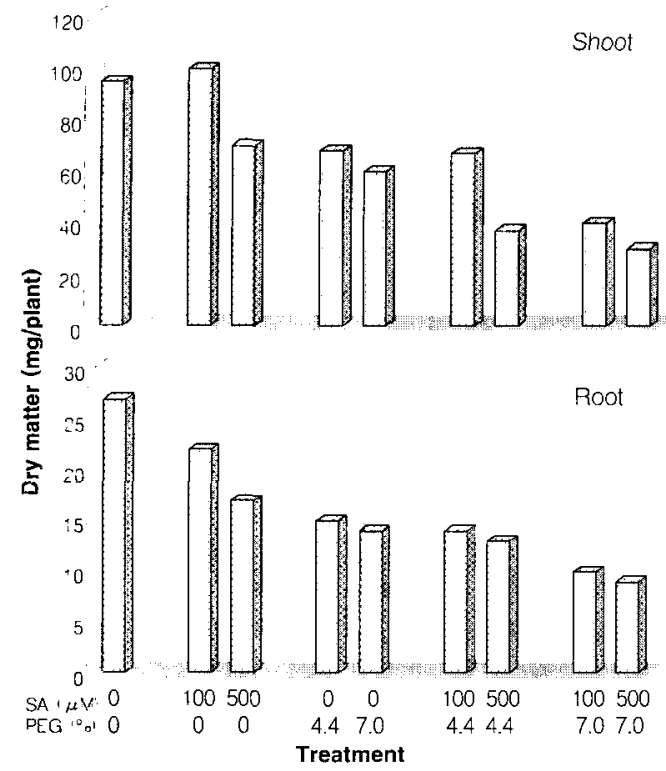

Fig. 5. Shoot and root dry matter of cucumber seedlings grown with SA and PEG alone and in combination.

PEG treatments(Fig. 5). Plants grown with 500 $\mathrm{M}$ SA $+7.0 \%$ PEG had $84 \%$ lower shoot dry matter than the control plants. SA reduced root dry matter most likely by reducing root elongation. The root length values decreased smaller to dry matter when the level of SA and PEG increased. Reductions in root length induced by SA+PEG were noted in this study. These stresses affected growth traits differently, although similarities of symptoms between SA and PEG stressed plants were apparent. Although plants were not grown to maturity, reductions in root length would likely cause significant reductions in leaf area and grain yields of mature plants ${ }^{33}$ ).

Shoot and roots of plants grown with SA had considerably lower proline than plants grown with PEG (Fig. 6). Shoots had higher proline than roots when plants were grown with either SA or PEG. Proline in shoots and roots were highest for plants grown with PEG. Plants grown with combinations of SA+PEG had higher shoot and root proline than plants grown with SA separately. Water deficit had greater effects on shoot and root proline accumulation than SA, and shoots had higher proline than roots. Proline was generally higher in shoots than in the roots as water deficit increased, which supports results of other studies ${ }^{34)}$. Plants growth with SA+PEG had much higher proline than plants grown with SA alone. Under some environmental stress conditions, proline accumulation may be an osmoregulatory process and may also protect cell membranes and enzymes.

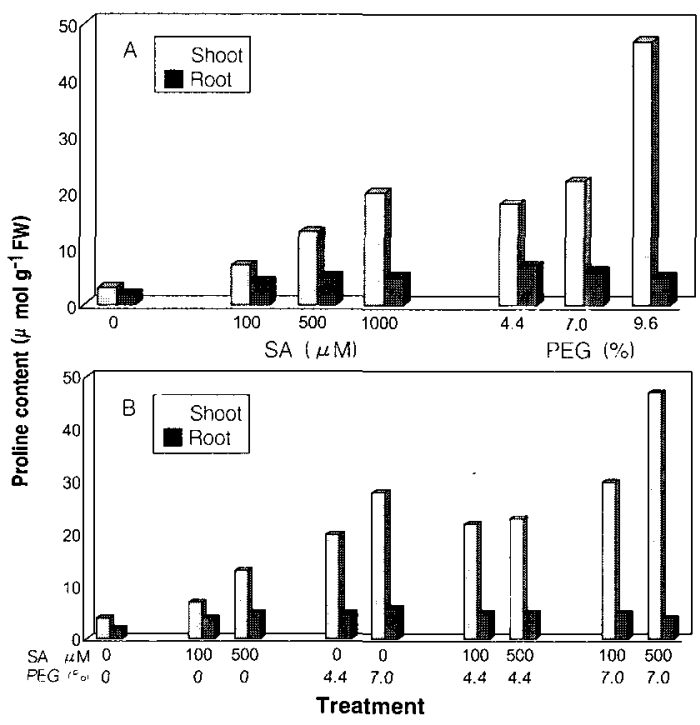

Fig. 6. Proline contents in shoots and roots of cucumber seedlings grown with SA and PEG alone(A) and in combination(B)

Proline accumulation could be a symptom of water deficit, and may not be directly involved in water deficit resistance. A strong correlation between high proline in seedlings and water deficit resistance did not support the concept that proline accumulation potential could serve as an index of water deficit resistance ${ }^{34)}$. In conclusion, this study contributes to define a role of SA during the osmotic stress, suggesting that SA increases the oxidative damage generated by osmotic stress ${ }^{35)}$.

\section{References}

[1] Raskin, I., Z. Skubatz, W. Tang and B. J. D. Meeuse, 1990, Salicylic acid levels in thermogenic and non-thermogenic plants, Ann. Bot. 66, $369 \sim 373$.

[2] Yalpini, N. and I. Raskin, 1993, Salicylic acid $:$ a systemic signal in induced plant decrease resistance, Trends in Microbiol. 1, 88 $\sim 92$.

[3] Raskin, I., 1992, Role of salicylic acid in plants, Annu. Rev. Plant Physiol. Plant Mol. 
Biol. $43,439 \sim 463$.

[4] Schettel, N. L. and N. E. Balke, 1983, Plant growth response to several allelopathic chemicals, Weed Sci. 31, 293 298.

[5] Bourbouloux, A., P. Raymond and S. Delrot, 1998 , Effect of salicylic acid on sugar and amino acid uptake, J. Exp. Bot. 49, $239 \sim 247$.

[6] Larque-Saavedra, A., 1979, Stomatal closure in response to acetylsalicylic acid treatments, Z. Pflanzenphysiol. 93, 371 2375 .

[7] Harper, J. R. and N. E. Balke, 1981, Characterization of the inhibition of $\mathrm{K}^{+}$ absorption in oat roots by salicylic acid, Plant Physiol. 68, 1349 1353.

[8] Leslie, C. and R. Romani, 1986, Salicylic acid : a new inhibitior of ethylene biosynthesis, Plant Cell Rep. 5, $144 \sim 146$.

[9] Nanda, K. K., S. Kumars and V. Sood, 1976, Effect of gibberellic acid and some phenols on flowering of Impatiens balsamica, a qualitative short-day plant, Physiol. Plant. 38, $53 \sim 56$

[10] Khurana, J. P. and S. C. Maheshwari, 1980, Some effects of salicylic acid on growth and flowering in Spirodela polyrisa $\mathrm{SP}_{20}$, Plant Cell Physiol. 21, 923 927.

[11] Elthon, T. E., R. L. Nickels and L. McIntosh, 1989, Mitochondrial events during the development of thermogenesis in Sauromatum guttattum(Schett), Panta 180, 82 89 .

[12] Rhoads, D. N. and L. McIntosh, 1991, Isolation and characterization of a cDNA clone encoding in alternative oxidase protein in Sauromatum guttatum (Schett), Proc. Natl. Acad. Sci. USA. 88, 2122 2126.

[13] Pancheva, T. V., L. P. Popova, 1998, Effect of salicylic acid on the synthesis of ribulose1,5-biphosphate carboxylase/oxygenase in barley leaves, Plant Physiol. 152. $381 \sim 386$.

[14] Maslenkova, L. and S. Toncheva, 1998, Salicylic acid-induced changes in photosystem $\amalg$ reaction in barley plants, Compt. Rend. Acad. Bulg. Sci. 51, $101 \sim 104$.

[15] Chandra, A. and R. K. Bhatt, 1998, Biochemical and physiological response to salicylic acid in relation to the systemic acquired resistance, Photosysnthetica 35, 255 258 .

[16] Yalpani, N., A. J. Enyedi, J. Leon and I. Raskin, 1994, Ultraviolet light and ozone stimulate accumulation of salicylic acid, pathogen-related proteins and virus resistance in tobacco, Planta 193, 372 376.

[17] Rao, M. V. and K. R. Davis, 1999, Ozoneinduced cell death occurs via two distinct mechanisms in Arabidopsis: the role of salicylic acid, Plant J. 17, 603 614.

[18] Janda, T., G. Szalai, I. Tari and E. Paldi, 1999, Hydroponic treatment with salicylic acid decreases the effects of chilling injury in maize(Zea mays L.) plants, Planta 208, 175 $\sim 180$

[19] Dat, J. F., H. Lopez-Delgado, C. H. Foyer and I. M. Scott, 1998, Parallel changes in $\mathrm{H}_{2} \mathrm{O}_{2}$ and catalase during thermotolerance induced by salicylic acid or heat acclimation in mustard seedlings, Plant Physol. 116, 1351 $\sim 1357$.

[20] Durner, J., J. Shah and D. F. Klessig, 1997, Salicylic acid and disease resistance in plant, Trends Plant Sci. 7, 266 274.

[21] Romeis, T., P. Piedras, S. Zhang, D. F. Klessig, H. Hirt and J. D. G. Jones, 1999, Rapid Avr 9-and Cf-9-dependent activation of MAP kinase in tobacco cell cultures and leaves: convergence of resistance gene, elicitior, wound and salicylate responses, Plant Cell 11, 273 287.

[22] Pancheva, T. V., L. P. Popova and A. N. Uzunova, 1996, Effects of salicylic acid on growth and photosynthesis in barley plants, J. Plant Physiol. 149, 57 63.

[23] Popova, L. P. and A. N. Uzunova, 1996, Changes in the chloroplast ultrastruture of barley leaves under treatment with jasmonic acid, Photosynthetica 32, 635 639 .

[24] Bohnert, H. J.,D. E. Nelson and R.G. Jenson. 1995, Adaptations to environmental stresses, Plant Cell 7, 1099 - 1111.

[25] Hare, P. D. and W. A. Cress, 1997, Metabolic implications of the stress-induced proline accumulation in plants, Plant Growth Regul. $21,79 \sim 102$.

[26] Kishor, K. P. B., Z. Hong, G. H. Miao, C. A. A. Hu and D. P. S. Verma, 1995, Overexpression of $\triangle^{1}$-pyroline-5-carboxylate synthetase increases proline production and confers osmotolerance in transgenic plants, Plant Physiol. 108, $1387 \sim 1394$. 
[27] Hoagland, D. R. and D. I. Arnon, 1950, The water-culture method for growing plants without soil. Calif. Agric. Exp. Bot. 37, 1036 -1043 .

[28] Bates, L. S., R. P. Waldren and I. B. Teare, 1973, Rapid determination of free proline for water-stress studies, Plant Soil 39, 205 207.

[29] Uzunova, A. N. and L. P. Popova, 2000, Effect of salicylic acid on leaf anatomy and chloroplast ultrastructure of barley plants, Photosynthetica $38,243 \sim 250$.

[30] Rai, V. K., S. S. Sharma and S. Sharma, 1986, Reversal of ABA-induced stomatal closure by phenolic compounds, J. Exp. Bot. 37, 129 $\sim 134$.

[31] Miteva, T. and S. G. Vaklinova, 1991, Photosynthesis, photorespiration and respiration in young barley upon influence of $\mathrm{NaCl}$, Compt. Rend. Acad. Bulg. Sci. 44, 89 -92.

[32] Popova, L. P., T. D. Tsoney and S. G.
Vaklinova, 1988, Changes in some photorespiratory and photosynthetic properties in barley leaves after treatment with jasmonic acid, J. Plant Physiol. 132, 257 - 261.

[33] Zaifnejad, M., R. B. Clark and C. Y. Sullivan, 1997, Aluminum and water stress effects on growth and proline of sorghum, J. Plant Physiol. 150, 338 344 .

[34] Verslues, P. E. and R. E. Sharp, 1999, Proline accumulation in maize(Zea Mays L.) primary roots at low water potentials. $\Pi$. Metabolic source of increased proline deposition in the elongation zone, Plant Physiol. 119, 1349 1360.

[35] Borsani, O., V. Valpuesta and M. A. Botella, 2001, Evidence for a role of salicylic acid in the oxidative damage generated by $\mathrm{NaCl}$ and osmotic stress in Arabidopsis seedlings, Plant Physiol. 126, 1024 1030. 